\title{
Cytoplasmic male killing elements in Adalia bipunctata (Linnaeus) (Coleoptera:Coccinellidae)
}

\author{
GREGORY D. D. HURST, MICHAEL E. N. MAJERUS \& LINDA E. WALKER \\ Department of Genetics, Downing Street, Cambridge CB2 3EH, U.K.
}

\begin{abstract}
A wild sample of Adalia bipunctata larvae and pupae were collected from Surrey, and $\mathrm{F}_{1}$ virgin adults mated. The sex ratio produced by these pairs was found be be variable, 22 pairs produced a sex ratio consistent with a 1:1 sex ratio, but four produced a strong female bias. Daughters and males from biased broods were mated to adults from non-biased broods of different parentage. Males and females from unrelated families were crossed. Where the female was taken from a biased clutch, the biased sex ratio trait recurred in a high proportion of cases. Where males from such broods were crossed, or females from broods with no history of bias were mated, sex ratios consistent with 1:1 were obtained. Pairs producing a strong female bias showed hatch rates which were approximately half that of crosses producing non-biased sex ratios. Treatment with tetracycline in golden syrup cured females who showed the biased sex ratio trait. Daughters conceived after this treatment produced normal sex ratios. Females fed purely on golden syrup, as a control, continued to produce female biased sex ratios until treated with tetracycline. We therefore suggest that an unknown bacterium, transmitted through egg cytoplasm but not sperm, is responsible for the early mortality of male embryos and thus a bias in the secondary sex ratio. The contribution that the study of the Coccinellidae can make to theories concerning the incidences and evolution of male killing elements is discussed in relation to egg cannibalism.
\end{abstract}

Keywords: Adalia bipunctata, cytoplasmic bacteria, dilution effect, female-biased sex ratio, kin selection, male killing.

\section{Introduction}

Why do different parents produce different sex ratios? Parents usually allocate resources equally to daughters and sons. However, there are exceptions (Karlin \& Lessard, 1986). The evolutionary causes of sex ratio variation may be classified into two types: either as an adaptation with regard to the interests of the parents, or as an adaptation with regard to particular genes within the organism but in conflict with the parental interest (see Charnov, 1982 for review).

In the first of these classes, we can, for instance, consider parents varying in condition and therefore allocation ability (Trivers \& Willard, 1973), or parents varying with respect to the degree of competition/cooperation between siblings and between siblings and

Correspondence: G. D. D. Hurst. parents (Hamilton, 1967; Werren, 1980; Taylor, 1981). Secondly, genes which affect the sex ratio that are inherited either on sex chromosomes or through the cytoplasm face different selection pressures with respect to the sex ratio from those on autosomes (Cosmides \& Tooby, 1981). A gene on one of the sex chromosomes that promotes its own inclusion into zygotes when in the heterogametic sex will spread and produce a biased sex ratio. This phenomenon of meiotic drive and concomitant sex ratio effects has recently been thoroughly reviewed (Whyttle et al., 1991). Its evolutionary consequences have been the subject of recent theoretical research (Frank, 1991; Hurst \& Pomiankowski, 1991; Haig \& Grafen, 1992). Cytoplasmic genes only gain transmission through females (Birky, 1978). They are at an evolutionary dead-end in males (Lewis, 1941; Hamilton, 1967). As a consequence a cytoplasmic gene with the 
ability to bias sex allocation towards daughters will spread. The means by which this bias is achieved include male sterility in hermaphroditic plants (Lewis, 1941), sex ratio biases via feminization (Legrand et al., 1987), male killing (Hurst, 1991) and parthenogenesis (Stouthamer et al., 1990). In addition, the evolutionary cause of such behaviours is becoming more clear (Frank, 1989; Taylor, 1990; Hurst et al., 1990; Hurst, 1991). The transmission of cytoplasmic genes solely through the female lineage underlies the evolutionary logic of sex ratio distortion in all these instances. Cytoplasmically inherited genes are known to affect primary sex ratios. A more widely observed distortion of allocation is the phenomenon of male killing by cytoplasmic elements. These have been characterized in diverse taxa including drosopholids (Magni, 1952), Lepidoptera (Clarke et al., 1983), Coleoptera (Lanier \& Oliver, 1966; Gotoh \& Niijima, 1986), Hemiptera (Leslie, 1984) and mosquitoes (Andreadis \& Hall, 1979). The evolutionary dynamics of this behaviour have been the subject of recent discussion (Uyenoyama \& Feldman, 1978; Werren, 1987; Hurst, 1991), and it is the postulated cause of sex ratio variation in Russian populations of Adalia bipunctata L. (the two spot ladybird) (Lus, 1947a).

In this paper, we demonstrate variation in the sex ratio of progeny produced by individual parents of $A$. bipunctata from a Surrey population: some pairs produced a 'normal' 1:1 sex ratio, others significantly female-biased ones. We subsequently show femalebiased sex ratios to be consistent with the death of male offspring early in their development and to be caused by a maternally inherited bacterium. This finding is, in itself, unremarkable. The prevalence of cytoplasmic sex ratio distorters in the Coccinellidae is, however, of great interest. The well investigated, tractable ecology of A. bipunctata, and the ease of handling of it and other Coccinellidae in the laboratory, make them highly suitable organisms for testing recent theories concerning the incidences and evolutionary causes of maternally inherited male killing elements.

\section{Variation in the sex ratio between crosses from the Surrey population}

\section{Method}

Adalia bipunctata larvae and pupae were collected from Juniper Hall field centre, Surrey, during July, 1990. A stock was set up. This stock was random with respect to any knowledge of sex ratio, but non-random with respect to colour pattern. $F_{1}$ virgins were isolated and a series of 20 randomly chosen pairs and seven pairs selected with regard to abnormal colour pattern were set up. In addition, one non-virgin female (which had mated with an unknown male) was allowed to produce progeny. The progeny from each of these 28 crosses were scored using morphological correlates of sex, as outlined in Randall et al. (1992). The efficiency of our sexing was tested by genital dissection, and found to be 98 per cent efficient on a sample of 150 of these progeny.

\section{Results}

The sex ratio derived from the above crosses showed a high level of variance, many individuals showing a sex ratio consistent with $1: 1$, but some showing a strong female bias (Table 1). Two crosses produced less than 10 progeny and were ignored in analysis. Statistical analysis of the crosses showed the crosses to be heterogeneous with respect to sex ratio $\left(\chi_{\nu=25}^{2}=47.93\right.$;

Table 1 The sex and sex ratio of progeny, measured on emergence as adults, from 26 crosses of adults derived from a Surrey population of Adalia bipunctata

\begin{tabular}{llllllll}
\hline Cross & Male progeny & Total progeny & SR (male/total) & Cross & Male progeny & Total progeny & SR (male/total) \\
\hline U1 & 33 & 65 & 0.51 & H14 & $\mathbf{1 4}$ & $\mathbf{4 6}$ & $\mathbf{0 . 3 0}$ \\
H1 & 21 & 43 & 0.49 & $\mathbf{H 1 5}$ & $\mathbf{1 0}$ & $\mathbf{3 0}$ & $\mathbf{0 . 3 3}$ \\
H2 & 13 & 24 & 0.54 & H16 & 18 & 38 & 0.47 \\
H3 & 10 & 17 & 0.59 & H17 & 23 & 49 & 0.47 \\
H5 & 41 & 86 & 0.48 & H18 & 24 & 53 & 0.45 \\
H6 & 11 & 19 & 0.58 & $\mathbf{H 1 9}$ & $\mathbf{1 1}$ & $\mathbf{4 1}$ & $\mathbf{0 . 2 7}$ \\
H7 & 28 & 53 & 0.53 & H21 & 44 & 85 & 0.52 \\
H8 & 9 & 17 & 0.53 & H22 & 7 & 12 & 0.58 \\
H9 & 15 & 35 & 0.43 & H23 & 26 & 66 & 0.39 \\
H10 & $\mathbf{1 3}$ & $\mathbf{7 1}$ & $\mathbf{0 . 1 8}$ & H24 & 28 & 59 & 0.47 \\
H11 & 13 & 28 & 0.46 & H25 & 10 & 20 & 0.50 \\
H12 & $\mathbf{6}$ & $\mathbf{1 9}$ & $\mathbf{0 . 3 1}$ & H26 & 14 & 30 & 0.47 \\
H13 & 38 & 82 & 0.46 & H27 & 16 & 24 & 0.67 \\
\hline
\end{tabular}


$P<0.005)$, the crosses being divisible into two groups, comprising five pairs (in bold in the figure) and 21 pairs respectively. Significant heterogeneity between these groups exists $\left(\chi_{\nu=1}^{2}=34.58 ; P<0.001\right)$, but there is no evidence of any heterogeneity within them (for femalebiased quintet, $\chi_{v=4}^{2}=3.80, P>0.40$; NS; for 21 with approximately $1: 1$ sex ratios, $\chi^{2}{ }_{\nu=20}=9.55 ; P>0.90$; $\mathrm{NS})$. Note that although $\mathrm{H} 12$ has been placed in the biased group, the low number of progeny produced make it possible that this bias is merely a sampling effect.

\section{Conclusion}

Variation in sex ratios exist in Surrey stocks of $A$. bipunctata, some pairs produce a female bias, others a 1:1 sex ratio consistent with random segregation of sex chromosomes and survival unbiased with relation to sex.

\section{The mechanism of sex ratio distortion}

\section{Method}

The following classes of cross were performed in an attempt to identify the mode of inheritance of the element.

(i) Daughter from female sex ratio bias cross $\times$ son from normal sex ratio cross.

(ii) Daughter from normal sex ratio cross $\times$ son from female sex ratio bias cross.

(iii) Female sibling of female used in (ii) $\times$ same males used in class $(i)$.

(iv) Daughter from normal sex ratio cross $\times$ son from normal sex ratio cross.

Individual females were allowed to mate repeatedly to the same male during the period of egg production. Where an individual male was used in two different crosses, males were alternated between females on a daily basis. For each cross, clutch sizes and egg hatch rates from each clutch were recorded. Progeny from the crosses were sexed soon after emergence as adults.

\section{Results}

The sex ratio trait was shown to be heritable through the female line only. The majority of daughters $(8 / 12)$ from crosses which produced a sex ratio bias (Class i) also produced a female bias. Some (4/12), however, produced normal sex ratios. All the crosses involving the sons of female-biased sex ratio clutches (Class ii) produced normal sex ratios. Daughters producing a strongly biased sex ratio also showed low egg hatch rates when compared to sisters which produced normal sex ratios and crosses involving brothers (Fig. 1). Regression analysis showed the relationship between the hatch rate and sex ratio observed to be linear $(F=58.1, P<0.0001$, significant $)$ and close to unity (slope $=0.97$ ). In addition, crosses producing no males had hatch rates half those of crosses in which the sex ratio produced was consistent with $1: 1$. One cross $(-$ Fig. 1), a daughter from a cross which produced a biased sex ratio (Class $i$ ), produced a biased sex ratio with low hatch rates at first, but later reverted to producing clutches with high hatch rates from which normal sex ratios were observed (see Fig. 2). This is equivalent to the 'retrogressive' sex ratio found in other coccinellids (Niijima \& Nakajima, 1981). The variance in sex ratio observed after the sixth clutch may be accounted for by the sampling effect of gametes at fertilization in clutches of up to 15 eggs. Other crosses, of types (iii) and (iv) above produced sex ratios consistent with parity (Fig. 3).

\section{Conclusion}

The above data strongly imply the presence of a cytoplasmically inherited element that distorts secondary sex ratios by killing males early in embryogenesis. This is said in the knowledge that primary sex ratio distortion, followed by random death with respect to the sex of embryos, is a possible, though theoretically highly unlikely, explanation.

Cytoplasmic elements which contain DNA are of four main types in animals: mitochondria (mutants of which are known to cause male sterility in plants), bacteria (known in many insects to cause sex ratio biases), viruses (associated with spiroplasmas in Droso-

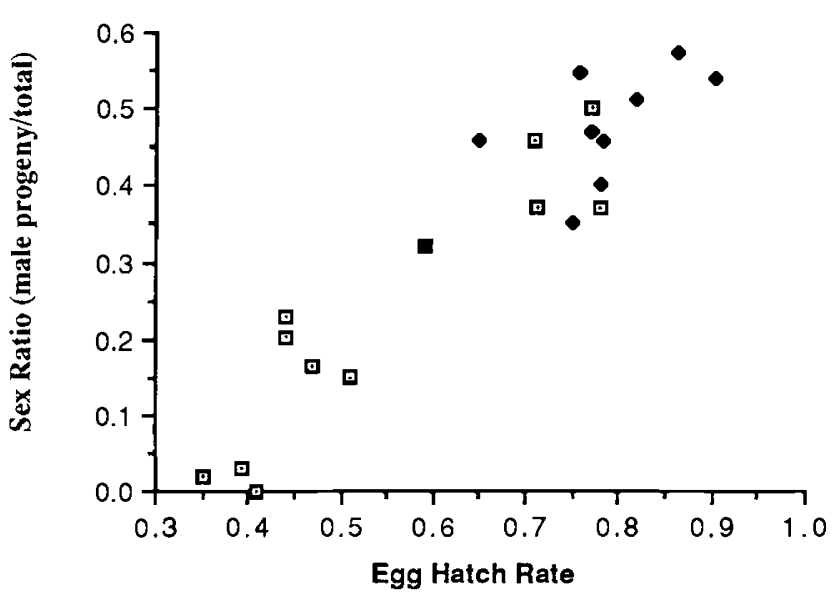

Fig. 1 The sex ratios (male progeny/total) and egg hatch rates shown by individuals in crosses involving daughters ( $v$ ) and sons $(\bullet)$ of parents which showed a sex ratio bias. The filled square represents the cross displaying the retrogressive sex ratio trait described in the text and Fig. 2. 


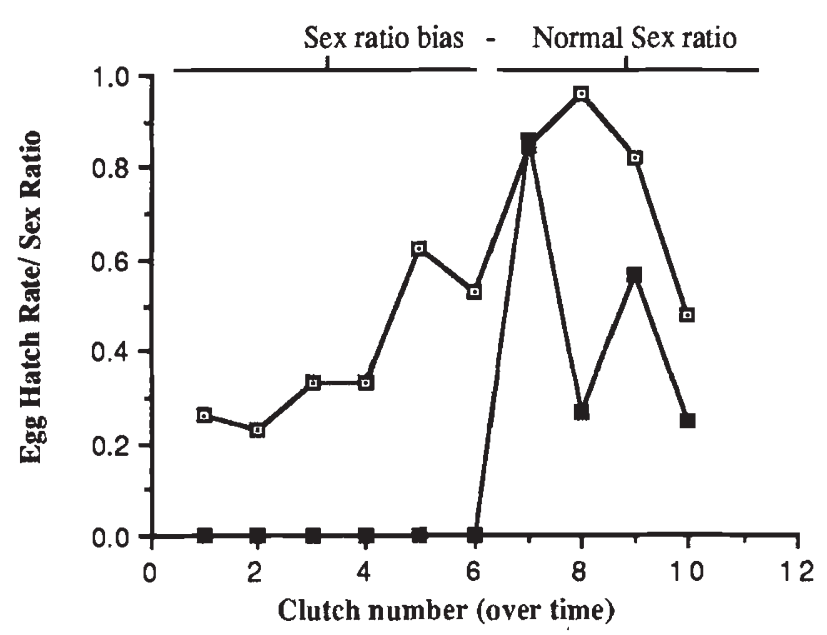

Fig. 2 The 'retrogressive' sex ratio trait shown in one cross. Egg hatch rates $(\square)$ and the sex ratio $(\square)$ are shown for sequential clutches of one cross. Overall sex ratio of cross $=0.33$.

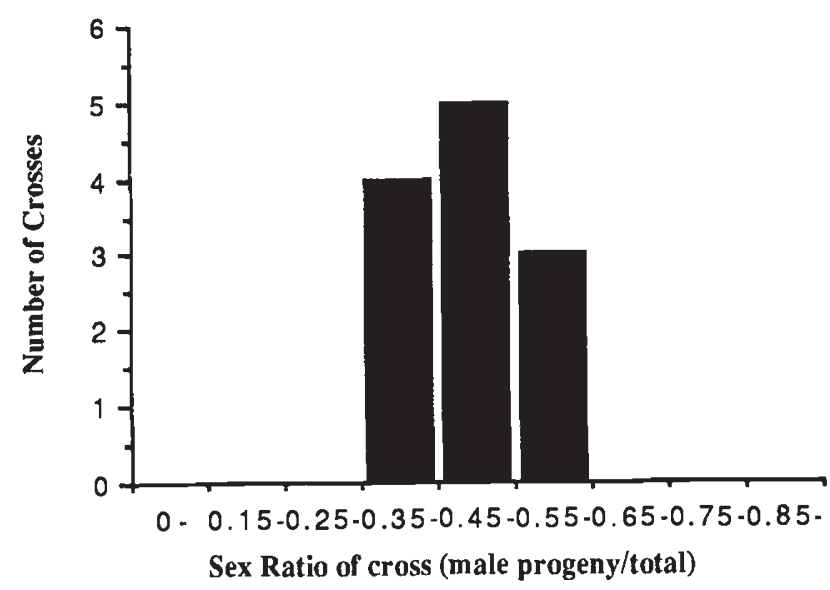

Fig. 3 The sex ratios in crosses involving the progeny of crosses showing a normal sex ratio.

phila) and protozoa (in mosquitoes). Work on other coccinellids has demonstrated, using a variety of antibiotics, the presence of tetracycline-sensitive male killing elements in two species (Gotoh \& Niijima, 1986). Consequently, attempts were made to cure the trait using tetracycline.

\section{Cure of trait}

Individual female ladybirds from lines which had shown a sex ratio bias were crossed to single males and assayed for the sex ratio condition over a 1-month period. After this time, irrespective of the sex ratio produced, the ladybirds were fed on one of two treatments in addition to their normal aphid diet. One group (A) was fed on a mixture of $100 \mathrm{mg}$ of the anti- biotic tetracycline in $1 \mathrm{~g}$ golden syrup. The other group (B) was fed on golden syrup without addition for 4 weeks, followed by tetracycline in golden syrup as before. The hatch rates of clutches and sex ratios produced from these clutches were assayed daily throughout this period.

To check whether tetracycline treatment produced a permanent cure, daughter progeny from both groups A and $B$ of known date of conception, i.e. some pre- and some post-treatment, were crossed to unrelated males. These crosses included some group B daughters conceived after golden syrup but before the addition of tetracycline. The progeny produced were assayed for sex ratio.

\section{Results}

Females which show the sex ratio trait prior to treatment in group A above were cured shortly after commencement of treatment with tetracycline in golden syrup, reverting to normal sex ratios and high hatch rates (Table 2). Females from group B, which showed the sex ratio trait continued to produce biased sex ratios while fed on golden syrup alone, but all reverted to a normal sex ratio shortly after treatment with tetracycline (Table 3). Neither treatment had any significant effect on the sex ratio or hatch rates shown by individuals which produced normal sex ratios (Table 4).

No individuals conceived after tetracycline treatment produced a biased sex ratio in the subsequent generation. Those conceived before treatment, or solely after treatment with golden syrup, produced a similar pattern of inheritance of the trait to that seen in the previous generation (Fig. 4).

\section{Conclusion}

The coccinellid, A. bipunctata, bears an element which distorts sex ratios by killing male progeny during embryogenesis, 'early' male killing (sensu Hurst, 1991). This element is tetracycline-sensitive, treatment with this antibiotic producing a permanent reversion to a $1: 1$ sex ratio. We therefore consider it highly probably that the element is a bacterium, inherited in the cytoplasm.

\section{Discussion}

Most discussions of novel instances of cytoplasmic bacteria have concentrated on hierarchical selection and the reasons for nuclear-cytoplasmic conflict. We shall not reiterate such discussions. Suffice it to say that the discovery that vertically transmitted bacteria kill males in Surrey populations of $A$. bipunctata reemphasizes the importance of conflicts between 
Table 2 The effect of treatment $\mathrm{A}$ (tetracycline in golden syrup) on the sex ratios and egg hatch rates produced in nine crosses showing a female biased sex ratio

\begin{tabular}{lllll}
\hline Cross & $\begin{array}{l}\text { Hatch rate, } \\
\text { pre-tetracycline }\end{array}$ & $\begin{array}{l}\text { Sex ratio, } \\
\text { pre-tetracycline }\end{array}$ & $\begin{array}{l}\text { Hatch rate, } \\
\text { post-tetracycline }\end{array}$ & $\begin{array}{l}\text { Sex ratio, } \\
\text { post-tetracycline }\end{array}$ \\
\hline B10:u & 0.43 & 0 & 0.79 & 0.42 \\
B10:a & 0.48 & 0 & 0.61 & 0.40 \\
B109:paB & 0.42 & 0 & 0.66 & 0.46 \\
B109:pFf & 0.37 & 0 & 0.55 & 0.38 \\
B109:pFh & 0.53 & 0.08 & 0.56 & 0.45 \\
B109:pAd & 0.30 & 0.04 & 0.56 & 0.40 \\
B15:d & 0.44 & 0.02 & 0.75 & 0.49 \\
B10:AL & 0.50 & 0.03 & 0.88 & 0.41 \\
Camb:B & 0.71 & 0.14 & 0.78 & 0.42 \\
\hline
\end{tabular}

Table 3 The effect of treatment B (golden syrup followed by tetracycline in golden syrup) on the sex ratio and egg hatch rates produced in six crosses showing a female-biased sex ratio

\begin{tabular}{lllllll}
\hline Brood & $\begin{array}{l}\text { Hatch rate, } \\
\text { pre-treatment }\end{array}$ & $\begin{array}{l}\text { Sex ratio, } \\
\text { pre-treatment }\end{array}$ & $\begin{array}{l}\text { Hatch rate, } \\
\text { golden syrup }\end{array}$ & $\begin{array}{l}\text { Sex ratio, } \\
\text { golden syrup }\end{array}$ & $\begin{array}{l}\text { Hatch rate, } \\
\text { +tetracycline }\end{array}$ & $\begin{array}{l}\text { Sex ratio, } \\
+ \text { tetracycline }\end{array}$ \\
\hline B109:pA & 0.27 & 0.10 & 0.32 & 0.04 & 0.63 & 0.63 \\
B109:pF & 0.43 & 0 & 0.40 & 0.15 & 0.64 & 0.41 \\
B109:pC & 0.52 & 0.04 & 0.41 & 0.06 & 0.58 & 0.34 \\
B109:pD & 0.31 & 0 & 0.34 & 0 & 0.65 & 0.51 \\
B109:pH & 0.34 & 0.04 & 0.42 & 0.06 & 0.50 & 0.35 \\
B109:kD & 0.47 & 0.32 & 0.41 & 0 & 0.53 & 0.37 \\
\hline
\end{tabular}

Table 4 The effect of treatment $\mathrm{A}$ (tetracycline in golden syrup) on the sex ratio and egg hatch rates produced in five crosses showing an even sex ratio

\begin{tabular}{lllll}
\hline Cross & $\begin{array}{l}\text { Hatch rate, } \\
\text { pre-tetracycline }\end{array}$ & $\begin{array}{l}\text { Sex ratio, } \\
\text { pre-tetracycline }\end{array}$ & $\begin{array}{l}\text { Hatch rate, } \\
\text { post-tetracycline }\end{array}$ & $\begin{array}{l}\text { Sex ratio, } \\
\text { post-tetracycline }\end{array}$ \\
\hline B10.45:yB & 0.74 & 0.38 & 0.86 & 0.51 \\
B109:pAL & 0.88 & 0.38 & 0.92 & 0.44 \\
B109:pAO & 0.82 & 0.47 & 0.73 & 0.40 \\
B109:pDF & 0.76 & 0.47 & 0.85 & 0.45 \\
Camb:A & 0.93 & 0.45 & 0.89 & 0.50 \\
\hline
\end{tabular}

nuclear and cytoplasmic elements in our understanding of evolution, as outlined in the introduction to this paper. It should also be noted that these elements are not confined to Surrey populations of $A$. bipunctata, homologous behaviour was also observed in Cambridge populations (G. Hurst, personal observation). Other authors have also speculated on the causes of female-biased sex ratios from Asian and Eastern European populations (Lus, 1947a), and a Staffordshire population (Kearns et al., 1992). The widespread existence of male killing behaviour in $A$. bipunctata raises several interesting questions and may aid in our understanding of others. One obvious question that arises concerns the mechanism by which the bacteria detects the sex of its host so early in embryogenesis. From this, the question as to how male killing is achieved is of interest. However, it is not just the bacterial strategy within males that is of interest. The means by which bacteria proliferate within female zygotes will also bear investigation, to ascertain whether, and, if so, how, vertical transmission efficiency is maximized while minimizing drains on host resources? Virtually nothing is known of the mechanism of early male killing, and research in this field is urgently needed.

We now turn to the contribution that a study of $A$. bipunctata may make to considerations of the incidences of and evolutionary logic underlying male kill- 


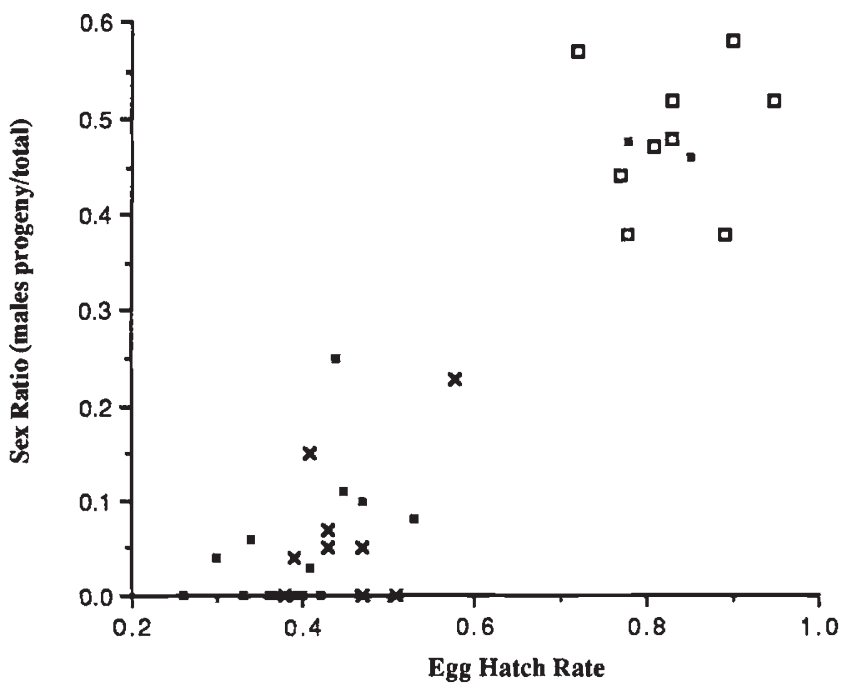

Fig. 4. A graph showing the sex ratios and egg hatch rates of crosses conceived at different times with respect to treatment with tetracycline in golden syrup. ( $)$ Conceived before treatment; $(X)$ conceived 1 week after treatment with golden syrup but before the addition of tetracycline; $(\square)$ conceived more than 1 week after treatment with tetracycline in golden syrup.

ing behaviour. Past theoretical constructs have interpreted male killing behaviour in the light of the low transmission of cytoplasmically inherited elements within males (Uyenoyama \& Feldman, 1978; Hurst, 1991). Male killing elements which cause male death early in the life history have been interpreted as being the evolutionary product of kin selection, the death of males increasing the fitness of the bacteria within female siblings of the dead male. The ecological circumstances which favour such behaviour explain the incidence of this behaviour and are discussed below. Male killing late in the life-span, on the other hand, is interpreted not in kin selective terms, but in terms of the cytoplasmically transmitted element, at a dead-end in males, promoting the horizontal transfer of the element in the manner adopted by most pathogens: replication within the host followed by dispersal into the environment. This is known in mosquitoes, where the death of males at the fourth instar allows the release of the parasite into the environment (Andreadis, 1985). The timing of male death is held to reflect the optimal proliferation time of the parasite within the organism (Hurst, 1991). The early timing of male killing in other cases is a reflection of the removal of competition at the earliest possible moment and therefore the freeing of resources for the longest length of time. No horizontal transmission is required or is envisaged.

Studies of Japanese coccinellids have, however, suggested that horizontal transmission of the male kill- ing bacterium between different host species may be a reality. Two species of coccinellid, Harmonia axyridis and Menochilius sexmaculatus have been extensively studied and have been shown to carry male killing, maternally inherited elements (Gotoh \& Niijima, 1986). The elements in the two species show similar antibiotic sensitivities. Cross-infection by microinjection was effected and resulted in the development of the trait with symptoms similar to those found naturally within each species. It was therefore considered that the elements responsible were identical.

The existence of interspecific transmission may explain the continued existence of these elements over evolutionary time. Given that selection will favour host resistance to the action of the bacterium if resistance has a low cost, then an arms race between the bacterium and the host would exist. The existence of an alternative pool of novel bacterial genotypes as a source of reinfection would increase the likelihood of the longterm survival of these male killers.

The question arises, however, as to how such a transfer could be naturally effected. The failure to culture many of the male killing bacteria in vitro, and the necessity to use tissue culture in Drosophila (Hackett et al., 1986) suggests that these elements may have high elements of specialization to their intracellular environment. We feel that this lack of longevity outside a host suggests that natural interspecific transmission is likely to be either direct or through an intermediary vector rather than contagious. In Drosophila, it has been put forward that P-elements may be tranferred interspecifically via a mite vector (Houck et al., 1991). Such mechanisms might also transfer male killing spiroplasmas in drosophilids. In coccinellids, however, it seems more likely that the transfer would be direct, via the predation of eggs of one species by another. Such interspecific predation is common in British coccinellids (M. E. N. Majerus, personal observation). If this is indeed a mechanism of transfer, then it would seem likely that intraspecific transfer might also occur during the cannibalistic acts, common in coccinellids (Hawkes, 1920). The existence of such intraspecific horizontal transmission would subtly alter the dynamics of male killing elements, and would require a third category of male killing behaviour to be considered: early male killing where low levels of horizontal transmission exist.

The study of distorted sex ratios in the Coccinellidae should contribute significantly to our understanding of the diversity of ecological scenarios that promote male killing behaviour. The data so far contained herein indicate that the transmission efficiency of bacteria from mother to adult daughter is around 85 per cent. This figure is broadly similar in the other two inten- 
sively studied coccinellids, $M$. sexmaculatus (Niijima \& Nakajima, 1981) and H. axyridis (Hu, 1979). Loss of the bacteria between parent and offspring can occur at two stages. Firstly, the element may segregate out during gametogenesis within the parent, such that some ova do not contain the element. This would explain the survival of some males in many crosses showing a biased sex ratio. Secondly, the bacteria may be lost after fertilization. Such reversions are most easily seen when they occur in reproductively active adults. Spontaneous reversion to normal sex ratios has been noted in females that initially produced female-biased sex ratios both in our study (the retrogressive sex ratio condition described in the text) as well as in $H$. axyridis (Hu, 1978) and M. sexmaculatus (Niijima \& Nakajima, 1981).

For the bacteria to be maintained in the population with such imperfect transmission, it is obvious that daughters bearing the bacteria must have a greater fitness (with respect to producing daughters) than females from clutches where all progeny survive. Females from biased sex ratio crosses must produce approximately 1.25 times as many surviving females as those not bearing it for maintenance of the bacterium at the observed levels in nature (5-10 per cent of wild caught females; G. Hurst, personal observation). The question arises as to the derivation of such a large advantage. Past authors have stressed two main points when considering the evolution of male killing bacteria: the advantage gained by the prevention of inbreeding by females bearing the bacterium, possessing few or no brothers in the population (Hodek, 1973; Werren, 1987; Ebbert, 1991) and the advantage gained through increased resources, either directly, due to the consumption of the soma of male eggs, or indirectly, due to decreased competition for resources suffered by females during early life (Hurst, 1991).

It is the purpose of this paper to encourage a pluristic approach to the ecological factors that give rise to conditions suitable for the evolution of male killing elements, not to put forward individual factors as important above others. Each organism should be treated on its merits. In the case of A. bipunctata, it is certain that profound inbreeding depression frequently occurs on sib-sib mating (Russian populations: Lus, 1947b; U.K. populations: G. Hurst, personal observation; Western Europe: M. E. N. Majerus, personal observation). However, the level of close inbreeding in the wild appears to be low (G. Hurst, personal observation of hatch rates from wild caught inseminated females). It could not, alone, account for the maintenance of the bacterium in the population, but may contribute to it. It is certain that sibling cannibalism occurs on unhatched eggs in the wild (Hawkes, 1920;
Banks, 1956) and that individuals that have cannibalized eggs are larger and have greater longevity (Banks, 1956). It is uncertain precisely how large a survival advantage this affords, and the advantage will almost certainly depend on variable features such as aphid distributions and densities in the wild. In addition, lowered competition early in life, for females in clutches where male killing has occurred is certainly likely, and at low aphid densities this may also increase the survival of females from such clutches to maturity. The advantages of male killing in $A$. bipunctata, however, are unlikely to be confined to these factors. Given that, on hatching, cannibalism of more slowly developing eggs of siblings occurs, and in general accounts for the death of 10 per cent of viable eggs, both in laboratory simulations (Banks, 1956) and in the wild (G. Hurst, personal observation), it seems highly likely that the number of females hatching from a clutch where male killing occurs is higher than that from comparable clutches where male killing does not occur. Female eggs hatching late are likely to be protected to a certain extent by a dilution effect (sensu Hamilton, 1971). Newly hatched larvae will have a choice of inviable male eggs and viable, late hatching female eggs. Therefore the probability of a viable egg being consumed will be reduced. In addition, as approximately only half the eggs hatch in affected clutches, the level of cannibalism will inevitably be reduced. The advantage to the bacterium may be substantial. This is a novel ecological advantage that may explain the high incidence of male killers within the cannibalistic members of the Cocinellidae.

\section{Acknowledgements}

The authors wish to thank Drs Laurence Hurst and Bill Amos for constant constructive discussions during this work. We are very grateful to $\mathrm{Mr}$ Dennis Parkinson, $\mathrm{Mr}$ Alan Feast and Mr Roger Ison for their invaluable assistance. The work was carried out in a laboratory funded by the Wolfson Foundation. Greg Hurst is the recipient of a grant from the SERC.

\section{References}

ANDREADIS, T. G. 1985. Experimental transmission of a microsporidian pathogen from mosquitoes to an alternate copepod host. Proc. Natl. Acad. Sci., U.S.A., 82, 5574-5577.

ANDREADIS, T. G. AND HALL, D. W. 1979. Significance of transovariol transmission of Amblyospora $\mathrm{sp}$ in relation to parasite maintenance in the mosquito Culex salinarius. $J$. Invert. Path., 34, 152-157. 
BANKS, C. J. 1956. Observations on the behaviour and early mortality of coccinellid larvae before dispersal from egg shells. Proc. Roy. Ent. Soc. Lond. A, 31, 56-61.

BIRKY, C. W. Jr 1978. Transmission genetics of mitochondria and chloroplasts. Ann. Rev. Genet., 12, 472-512.

Charnov, E. L. 1982. The Theory of Sex Allocation. Princeton University Press, New Jersey.

ClARKE, C., Johnston, G. \& Johnston, B. 1983. All female broods in Hypolimnas bolina (L.) A resurvey of West Fiji after 60 years. Biol. J. Linn. Soc., 19, 221-235.

COSMIDES, L. M. \& TOOBY, J. 1981. Cytoplasmic inheritance and intragenomic conflict. J. Theor. Biol., 89, 83-129.

EBBERT, M. 1991. The interaction phenotype in the Drosophila willistoni - spiroplasma symbiosis. Evolution, 45, 971-988.

FRANK, S. A. 1989. The evolutionary dynamics of cytoplasmic male sterility. Am. Nat., 133, 345-376.

FRANK, S. A. 1991. Divergence of meiotic drive suppression systems as an explanation for biased hybrid sterility and inviability. Evolution, 45, 262-267.

GOTOH, T. AND NIIJIMA, K. 1986. Characteristics and agents of abnormal sex ratio in two aphidophagous coccinellid species. In: Hodek, I (ed.) Ecology of the Aphidophaga, Academia, Prague, pp. 545-550.

HACKETT, K. J., LYNN, D. E., WILLIAMSON, D. L., GINSBERG, A. S. AND WHITCOMB, R. F. 1986. Cultivation of Drosophila sex ratio spiroplasma. Science, 232, 1253-1255.

HAIG, D. AND GRAFEN, A. 1992. Genetic scrambling as a defence against meiotic drive. J. Theor. Biol., 153, 531-538.

HAMILTON, w. D. 1967. Extraordinary sex ratios. Science, 156, 477-488.

HAMilton, w. D. 1971. The geometry of the selfish herd. $J$. Theor. Biol., 31, 295-311.

HAWKES, O. A. M. 1920. Observations on the life history, biology and genetics of the ladybird beetle Adalia bipunctata. Proc. Zool. Soc., 33, 475-489.

HODEK, 1. 1973. The Biology of the Coccinellidae. Academia, Prague.

HOUCK, M. A., ClARK, J. B., PETERSON, K. R., AND KIDWELl, M. G. 1991. Possible horizontal transfer of Drosophila genes by the mite Proctolaelaps regalis. Science, 253, 1125-1129.

HU, H. 1979. Maternally inherited 'sonless' abnormal sex ratio condition in the ladybeetle Harmonia axyridis. Acta Genet. Sin., 6, 296-304 (in Chinese).

HURST, L. D. 1991. The incidences and evolution of cytoplasmic male killers. Proc. Roy. Soc. Lond. B, 244, 91-99.

HURST, L. D., GODFRAY, H. C. J. AND HARVEY, P. H. 1990. Antibiotics cure asexuality. Nature, 346, 510-511.

HURST, L. D. AND POMIANKowski, A. 1991. Causes of sex ratio bias may account for unisexual sterility in hybrids: a new explanation for Haldane's rule and related phenomena. Genetics, 128, 841-858.

Karlin, s. AND Lessard, s. 1986. Theoretical Studies on Sex
Ratio Evolution. Princeton University Press, New Jersey.

KEARNS, P. W. E., TOMLINSON, I. P. M., VELTMANN, C. J. AND O'DONALD, P. 1991. Non-Random mating in the two spot ladybird, Adalia bipunctata. II Further tests for female mate preference. Heredity, 68, 385-389.

LANIER, G. N. AND OLIVER, J. H. 1966. Sex ratio condition: an unusual mechanism in bark beetles. Science, 153, 208-209.

LEGRAND, J. J., LEgRAND-HAMELin, E. AND JuCI, P. 1987. Sex determination in Crustacea. Biol. Rev., 62, 439-470.

LESLIE, J. F. 1984. A sex ratio condition in Oncopeltus fasciatus J. Hered., 75, 260-264.

LEwIS, D. 1941. Male sterility in natural populations of hermaphroditic plants: The equilibrium between females and hermaphrodites to be expected with different types of inheritance. New Phytol., 40, 56-63.

LUS, Y. Y. $1947 \mathrm{a}$. Some rules of reproduction in populations of Adalia bipunctata: non-male strains in populations. Dokl. Akad. Nauk SSSR, 57, 951-954.

LUS, Y. Y. $1947 \mathrm{~b}$. Some rules of reproduction in populations of Adalia bipunctata: heterozygosity of lethal alleles in populations. Dokl. Akad. Nauk SSSR, 57, 825-828.

MAGN1, G. 1952. Sex ratio in Drosophila bifaciata. First Lombardo Sci. Lett., 85, 274-286.

NilJMA, K. AND NAKAJMA, K. 1981. Abnormal sex ratio in Menochilius sexmaculatus (Fabricius). Bull. Fac. Agric. Tamagawa Univ., 21, 59-67. (in Japanese).

RANDALL, K., MAJERUS, M. E. N. AND FORGE, H. 1992. Characteristics for sex determination in British ladybirds Coleoptera:Coccinellidae. Entomologist, (in press).

STOUTHAMER, R., LUCK, R. F. AND HAMILTON, W. D. 1990. Antibiotics cause parthenogenetic Trichogramma (Hymenoptera/Trichogrammatidae) to revert to sex. Proc. Natl. Acad. Sci. U.S.A., 87, 2424-2427.

TAYLOR, D. R. 1990. Evolutionary consequences of cytoplasmic sex ratio distorters. Evol. Ecol., 4, 235-248.

TAYLOR, P. D. 1981. Intra- and Inter-sex interaction as sex ratio determinants. Nature, 291, 64-66.

TRIVERS, R. L. \& WILLARD, D. E. 1973. Natural selection of parental ability to vary the sex ratio of offspring. Science, 179, 90-92.

UYENOYAMA, M. K. \& FELDMAN, M. W. 1978. The genetics of sex ratio distortion by cytoplasmic infection under maternal and contagious transmission: an epidemiological study. Theor. Pop. Biol., 14, 471-497.

WERREN, J. H. 1980. Sex ratio adaptations to local mate competition in a parasitic wasp. Science, 208, 1157-1159.

WERREN, J. H. 1987. The coevolution of autosomal and cytoplasmic sex ratio factors. J. Theor. Biol., 124, 317-334.

WHYTTLE, T., SANDLER, L. M., PROUT, T. AND PERKINS, D. T. 1991. The genetics and evolutionary biology of meiotic drive. Discussion symposium on meiotic drive. Am. Nat., 137, 281-456. 